\title{
Memory and the experience of duration in retrospect*
}

\author{
RICHARD A. BLOCK $\dagger$ \\ University of Oregon, Eugene, Oregon 97403
}

\begin{abstract}
Two experiments investigated the relationship between long-term memory for events occurring during an interval and the experience of duration of the interval in retrospect. In both, Ss attended to a sequence consisting of a standard, an experimental. and a second standard interval. Then unexpected comparative duration and memory judgments were requested. In Experiment I, either 30 or 60 unrelated words occurred during the 180 -sec experimental interval. When more words had occurred, judgments of duration of the experimental interval, judgments of number of words presented, and number of words recognized all increased, but free recall of words was unaffected. In Experiment II, 80 categorized words occurred during the $160-\mathrm{sec}$ experimental interval, with category instances in either blocked or random order. When words were blocked by category, judgments of duration of the experimental interval, free recall, and recognition all increased, but judgments of number of words were unaffected. Results were discussed in terms of Ornstein's (1969) "storage size" hypothesis.
\end{abstract}

Some of the first philosophers and psychologists who discussed the experience of duration realized that it must be intimately related to memory processes. Aristotle thought that "only those animals which perceive time remember, and the organ whereby they perceive time is also that whereby they remember [McKeon, 1941. pp.607-608]." More recently, a number of psychologists have proposed a distinction between the experience of duration in passing and in retrospect, postulating separate mechanisms to account for the two types of temporal experience. As the term is typically used, "the experience of duration in passing" refers to the awareness of the apparent length of an interval between a past event and the psychological present. On the other hand, "the experience of duration in retrospect" typically refers to the awareness of the apparent length of an interval between two past events.

There is little agreement among theorists concerning the processes underlying the experience of duration in passing. However, contemporary theorists, along with Aristotle, generally agree that memory plays a central role in the experience of duration in retrospect (e.g.

\footnotetext{
* This article is based on a PhD dissertation submitted to the University of Oregon. The author wishes to thank members of the dissertation committee-Douglas L. Hintzman. Michael I. Posner. Wayne A. Wickelgren, and Don S. Levi-for criticism and advice. Thanks are also due Jean $\mathrm{F}$. Block. David R. Gostnell. and A. John Wisdom for comments on an earlier version of the manuscript. The research was supported by Predoctoral Fellowship 2-F01-MH48356-02 from the National Institute of Mental Health, U.S. Public Health Service, and by a grant to Douglas L. Hintzman from the Office of Education. L.S. Department of Health. Education, and Welfare. Contractors undertaking such projects under government sponsorship are encouraged to express freely their professional judgment in the conduct of the project. Points of view or opinions stated do not. therefore, necessarily represent official Office of Education position or policy

$\doteqdot$ Requests for reprints should be sent to Richard A. Block. Department of Psychology, State University of New York. Plattsburgh. New York 12901
}

Frankenhaeuser, 1959; Ornstein, 1969; Michon, 1970). Since memory is assumed to be involved, the present paper explores the role of long-term memory in determining the retrospective experience of duration of relatively long intervals.

Although there has been much theoretical speculation about the role of memory in the experience of duration, only a few investigators have attempted to determine experimentally which aspects of memory might be involved. Frankenhaeuser (1959. Experiments 3 and 4) studied the relationship between memory for the number of events that occurred during an interval and retrospective estimates of duration of the interval. In these experiments, Ss read random digits until stopped. Then they estimated either the duration of the interval, the number of digits read, or both. There was a close correspondence between the two types of estimates over intervals ranging in duration from 4 to $53 \mathrm{sec}$. The interpretation of these results, however, is complicated by the fact that Ss were tested repeatedly and were aware that duration judgments would be requested at the end of some of the intervals. Under these circumstances, Ss might have adopted a special strategy for making judgments of duration. Thus, the degree of correspondence between the two types of judgments might have been somewhat artifactual and possibly not generalizable to situations in which $S$ s are not aware that duration judgments would be requested at the end of the interval.

Using a paradigm in which Ss were not aware that duration judgments would be requested. Ornstein (1969) conducted several experiments in which both memory for the contents of an interval and judgments of duration were measured. In one of them (Experiment VII), Ss learned either of two different paired-associate lists for $6 \mathrm{~min}$, and they were asked to make a comparative magnitude judgment of duration of the learning task after either no delay or a 2-week delay. Duration judgments were closely paralleled by a memory 
measure. the number of response terms correctly retained on a subsequent test trial. In two other experments (Experiments VIII and IX). Ss viewed a line figure for $1 \mathrm{~min}$. The complexity of the coding of the figures was presumably varied across $\mathrm{Ss}_{\mathrm{g}}$ by establishing either a simple or a more comples "set. " Memory was assessed by requesting a rerbal description of the figure. As the complexity of the coding of the figure increased. retrospective duration judgments increased. as did the mean number of words used to describe the figure.

Based on the results of these and other experiments. Ornstein proposed what is currently the most specific hypothesis relating memory processes and the experience of duration. although. as Ornstein admitted, the hypothesis is still quite vague. The experience of duration is assumed to be a cognitive construction (cf. Neisser, 1967) based on the "storage size" of the interval. as it is assessed by the $\mathrm{S}$ at the lime the duration judgment is made. In addition. the storage size of an interval is assumed to increase as two general factors increase: (1) the number of events stored and retrieved and $(2)$ the complexity of the coding of the erents at the time of retrieval. Although Ornstein stated that storage size could never really be measured. he gave considerable theoretical emphasis to those experiments in which he attempted to measure it.

The present paper reports two experiments designed to test the assumptions underlying Ornstein's storage size hypothesis and to determine whether some common measures of memory might be used to assess the storage size of an interval. Experiment $I$ investigated several effects of the number of events that occurred during an interval. while Experiment II investigated effects of the complexity of the series of events that occurred. Both used essentially the same method. The Ss attended to a sequence of events consisting of three segments: a standard interval of music. an experimental interval during which words were presented, and a second standard interval of music. In each experiment there were two main experimental conditions, differing only in the events that occurred during the experimental interval. A between-Ss design was used in order to minimize the possibility that Ss, in making duration judgments. would compensate for the effect of the experimental manipulation on them. After attending to the three intervals. the $S_{s}$ were unexpectedly asked to make three comparative judgments of duration. with each of the intervals being compared with each other interval. Finally. Ss were given three memory tasks designed to measure memory for the events that occurred during the experimental interval: free recall, recognition, and judgment of the number of events that occurred. The duration judgments always preceded these memory tasks, since it was unlikely that the former would affect the latter, and with this arrangement the latter could not affect the former.

\section{EXPERIMENT I}

Many investigators have reported that the retrospective experience of duration of an interval increases as a function of the number of erents that occurred during the interval (for reviews. see Fraisse. 1963: Ornstein. 1969). In Experiment I. which was designed to investigate this phenomenon. two experimental conditions differed only in the number of words that occurred during the experimental interval. The usual finding. at least under certain conditions. is that the number of unrelated words that can be correctly recalled from an interval is constant for intervals of the same duration and does not depend upon the number of words that actually occurred (cf. Cooper \& Pantle, 1967). If the experience of duration is based on the number of nominal stimulus events that can be correctly recalled from the interval, then duration judgments should not differ for the two conditions. If. on the other hand, the experience of duration is based on some other aspect of memory, then duration judgments for the two conditions might differ.

\section{Method}

\section{Materials and Design}

An audio tape consisting of three segments was recorded using a stereo tape recorder. A tone delimited the start and end of each segment, and there was a 5 -sec blank interval between segments. The first segment was a 240 -ses excerpt of electronic music from karlheinz Stockhausen's Kontakte. Identical monophonic copies were simultaneously recorded on both channels of the tape. The second segment was a 180 -sec series of words spoken by a male voice. A pool of 90 common three-letter English words was used in the experiment. $t$ total of 60 of these words was randomly selected. and 30 were randomly assigned to each of the channels: the other 30 words did not occur on the tape but were used as distractor words on the recognition test. The experimental words were randomized, then recorded on the appropriate channel of the tape. There was a 6-sec onset-to-onset interval between consecutive words on a given channel and a 3 -sec interval between words alternating across channels. A different random selection and ordering of the words was also recorded. and approsimately half of the S、 received each version. During each experimental session. either one channel of the tape was amplified or both channels were amplified. depending upon the experimental condition to which the $S$ s had been assigned. If only one channel was amplified. for approximately half the $S$ i it was the left channel and for half it was the right. Since the two channels differed only in the second segment of the tape, the two main experimental conditions differed only in the total number of words presented land. hence. in the rate of presentation) during the second segment. The $S s$ in one condition (Group 30 ) heard 30 words presented at a 6 -sec rate. While those in another condition (Group 60 ) heard 60 words presented at a $3-\mathrm{sec}$ rate. The third segment of the tape was a $120-s e c$ excerpt from a different part of Kontakte. with an identical monophonic copy recorded on each channel as before.

A booklet of duplicated test forms, with instructions printed at the top of each, was used for both the duration judgments and the memory tests. Three similar test forms were used for comparative judgments of duration (cf. Ornstein. 1969). On each. two lines appeared below the instructions. a $50-\mathrm{mm}$ ine representing the comparison interval above a $100-\mathrm{mm}$ line representing the judged interval. To the left of each line was a verbal label. "First segment: Electronic music." "Second segment: English words. " or "Third segment Llectronic music," depending upon which interval was being described. On the first test form. the second segment was judged in comparison to the first segment: on the secund test form. the vecond verment wa 
Table 1

Mean and Standard Deviation (in Parentheses) for Each Measure for Groups 30 and 60: Experiment I

\begin{tabular}{|c|c|c|c|c|c|c|c|c|c|c|}
\hline \multirow{3}{*}{ 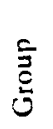 } & \multicolumn{3}{|c|}{ Duration Judgments } & \multicolumn{2}{|c|}{ Free Recall } & \multirow{3}{*}{$\begin{array}{c}\text { Judgment } \\
\text { of Number } \\
\text { Presented }\end{array}$} & \multicolumn{4}{|c|}{ Recognition (Forced-Choice) } \\
\hline & Segment & Segment & Segments & \multirow{2}{*}{$\begin{array}{l}\text { Number } \\
\text { Correct }\end{array}$} & \multirow{2}{*}{$\begin{array}{l}\text { Number } \\
\text { Produced }\end{array}$} & & & Corrected & & $d^{\prime}$ \\
\hline & $2: 1$ & $2: 3$ & $3: 1$ & & & & Corrected & Total & $d^{\prime}$ & Total \\
\hline 30 & $\begin{array}{c}0.79 \\
(0.24)\end{array}$ & $\begin{array}{l}1.40 \\
(0.32)\end{array}$ & $\begin{array}{c}0.60 \\
(0.20)\end{array}$ & $\begin{array}{c}10.9 \\
(4.2)\end{array}$ & $\begin{array}{c}13.5 \\
(4.6)\end{array}$ & $\begin{array}{c}30.4 \\
(8.7)\end{array}$ & $\begin{array}{c}21.3 \\
(6.0)\end{array}$ & $\begin{array}{c}21.3 \\
(6.0)\end{array}$ & $\begin{array}{c}1.69 \\
(0.81)\end{array}$ & $\begin{array}{c}50.8 \\
(24.3)\end{array}$ \\
\hline 60 & $\begin{array}{c}0.95 \\
(0.28)\end{array}$ & $\begin{array}{c}1.47 \\
(0.37)\end{array}$ & $\begin{array}{c}0.65 \\
(0.19)\end{array}$ & $\begin{array}{c}11.0 \\
(4.5)\end{array}$ & $\begin{array}{c}14.7 \\
(5.1)\end{array}$ & $\begin{array}{c}39.7 \\
(12.1)\end{array}$ & $\begin{array}{c}14.2 \\
(6.7)\end{array}$ & $\begin{array}{c}28.4 \\
(13.4)\end{array}$ & $\begin{array}{c}0.93 \\
(0.50)\end{array}$ & $\begin{array}{r}55.7 \\
(29.7)\end{array}$ \\
\hline
\end{tabular}

judged in comparison to the third segment; and on the third test form, the third segment was judged in comparison to the first segment. Except for the printed instructions. the test sheets for free recall and judgment of number of words were both blank. For each version of the word segment, two forced-choice recognition test forms were constructed. On one of them, each word that had occurred on the left channel of the tape was randomly paired with a distractor word; on the other. each corresponding word from the right channel was paired with the same distractor word. The overall order of the word pairs, as well as the within-pair order of the words, was random.

\section{Subjects}

The Ss were 66 paid volunteers. both male and female, obtained through an advertisement in the University of Oregon campus new spaper. The advertisement informed them that the experiment would last less than $1 \mathrm{~h}$. The $\mathrm{Ss}$ were tested in groups of eight to ten, and each group was assigned to one of the two main experimental conditions in a counterbalanced order across testing sessions. The data of an additional four Ss were discarded because of their failure to follow instructions.

\section{Procedure}

At the outset. general instructions were played over the tape recorder. These instructions informed the Ss that they would hear a tape recording consisting of three segments: one segment of electronic music. one of English words, and another of music. They were told to pay close attention to the tape. since they would be asked some questions about it later. They were not informed beforehand of any of the tasks that would follow. The tape recording was then played. using two loudspeakers located side by side at the front of the room.

Test booklets were distributed immediately following the end of the tape. The Ss were instructed not to look at preceding or succeeding test forms. The instructions printed at the top of each test form were read to $\mathrm{Ss}$. For all $\mathrm{S}$ s. the following amounts of time, including that taken to read instructions. were allocated for each test sheet: the three duration judgments. 1.5 min each: free recall. $5 \mathrm{~min}$; recognition. $3 \mathrm{~min}$; and judgment of number of words, $1 \mathrm{~min}$.

The instructions for each of the comparative duration judgments were similar to those used by Ornstein (1969): The Ss were asked to delimit a line length on the bottom line which corresponded to the subjective duration of the judged interval relative to the top line length which represented the subjective duration of the comparison interval. For the free recall test. the Ss were told to write down in any order all of the words they could remember. For the forced-choice recognition test. they were told to circle the one word of each pair that they thought had been presented during the second segment. All Ss were tested on exactly 30 pairs of words. The $S s$ in Group 30 received the recognition test form appropriate to the channel of the tape which had been amplified. while those in Group 60 received a test form appropriate to one randonly selected channel of the two which had been amplified. For the judgment of number of words. Ss were told to give a numerical estimate of the number of words that had occurred during the second segment. Across testing sessions, approximately half of the Ss (including an equal number from Group 30 and Group 60) completed the recognition test before judging the number of words, and the other half performed the two tasks in the reverse order.

\section{Results and Discussion}

In Table 1, the mean and standard deviation for each measure obtained in Experiment $I$ are shown separately for Group 30 and Group 60. The tasks are listed in the order in which they were performed (except for the last two tasks, as described above), and they will be discussed in the same order.

\section{Duration Judgments}

Duration judgments were measured as the ratio of the length of the judged line segment to the length of the comparison line segment. For the first duration judgment, the mean ratio of the judged length of the word interval to the comparison length of the first music interval was significantly greater for Group 60 than for Group $30[\mathrm{t}(64)=2.56, \mathrm{p}<.02]$. Thus, in comparison to the first music interval, retrospective duration judgments of the word interval were greater when more words had been presented during the interval. For the second duration judgment, the mean ratio of the judged length of the word interval to the comparison length of the second music interval did not differ significantly between the two groups $[t(64)=0.85, p>.05]$. There was, however, a significant correlation between individual S's first and second duration judgments $[r(64)=+.39, p<.01]$, indicating that the word interval was judged in a similar way in comparison to the two music intervals. The reason for the failure to obtain a significant difference between the two groups on the second duration judgment is unclear. One possibility, however, is that the second judgment was affected in some way by the preceding judgment, since the order of the judgments was not varied. For the third duration judgment, the mean ratio of the judged length of the second music interval to the comparison length of the first music interval was not significantly different between the two groups $[t(64)=1.05, p>.05]$. Thus. both groups judged the relation between the durations of the two music intervals in a similar way. For individual Ss. the third duration judgment was significantly correlated with both the first duration 
judgment $[r(64)=+.27 . \quad p<.05]$ and the second duration judgment $[\mathrm{r}(64)=-.56 . \mathrm{p}<.001]$. revealing a further consistency in duration judgments that involve a common interval. (The negative correlation was expected because the third interval was the comparison interval for the second judgment and the judged interval for the third judgment.) Of course, caution must be exercised in interpreting the results of the latter two judgments. since they may have been influenced by memory for the preceding judgments made.

\section{Free Recall}

As expected on the basis of some previous findings (cf. Cooper \& Pantle, 1967), the mean number of words correctly recalled did not differ significantly between Group 60 and Group $30 \quad[\mathrm{t}(64)=0.08, \mathrm{p}>.05]$. In addition. the two groups did not differ significantly in the mean number of words produced in free recall, regardless of whether each recalled word had actually been presented $[t(64)=0.97, p>.05]$. These findings suggest that the difference between the two groups on the first duration judgment cannot be interpreted as being based on differences in the number of events recalled. Thus. Ornstein's (1969, Experiment VII) finding of a close correspondence between the number of paired-associate response terms correctly recalled and retrospective duration judgments is not a general one.

\section{Judgment of Number of W'ords}

The mean judgment of number of words presented was significantly greater for Group 60 than for Group 30 $[\mathrm{t}(64)=3.56, \mathrm{p}<.001]$. This result. which is consistent with that of Frankenhaeuser (1959). suggests that the experience of duration might involve a memory process similar to that which underlies judgments of the number of events that occurred during the interval. It was assumed that the difference between groups in judged number of words was not artifactually produced by the preceding recall test, since the two groups did not differ on that test. It is possible. however. that the magnitude of the difference between the groups was reduced by the preceding free recall test. Furthermore, these judgments did not depend on whether they preceded or followed the recognition test. Neither the main effect of test order $[F(1.30)=3.15, p>.05]$ nor the interaction of Test Order by Groups $[F(1.30)=0.24, p>.05]$ was significant.

\section{Recognition}

Two commonly used measures of recognition performance are a standard correction for guessing and the more recently proposed d' measure. The two measures differ in the assumptions made about the underlying memory and decision processes (cf. Kintsch. 1970). Since there is still some disagreement over which of the measures makes reasonable assumptions in any given situation. analyses using both measures are reported here.

Using a standard correction for guessing. for each $\mathrm{S}$ an estimate was computed of the number of words about which sufficient information was stored and retained in memory to support recognition on the forced-choice test. The number of words correctly recognized by each $S$ was corrected for guessing by assuming that $S$ was guessing on $2 \mathrm{i}$ pairs. where $\mathrm{i}$ equals the number of incorrect test pairs. Group 60. however, was tested on only half of the words that had been presented. and it seems reasonable to assume that recognition would have been comparable on the untested words. Thus. the corrected recognition score of each $S$ in Group 60 was multiplied by 2 . The resulting mean corrected total recognition score was significantly greater for Group 60 than for Group $30[t(64)=2.77 . p<.01]$. Using the $d^{\prime}$ measure. an estimate of the average memory strength (d') of the presented words was obtained for each S. If one is willing to make the strong assertion that the individual $\mathrm{d}^{\prime}$ values can be legitimately multiplied by the number of words presented to each $S$, then a measure of the total memory strength ( $d^{\prime}$ total) of the word segment is obtained. The mean of the resulting $\mathrm{d}^{\prime}$ total scores did not differ significantly between the two groups $[t(64)=0.74 . p>005]$. Even though the d' total statistic does not reveal any significant difference in recognition performance between the two groups. it appears that whatever aspects of memory underlie recognition performance (as measured by the corrected total recognition score) might also underlie the experience of duration in retrospect.

This tentative conclusion depends on the assumption that performance on the recognition test was essentially. unaffected by the preceding free recall test. There is some evidence for this assumption (cf. Darley \& Murdock, 1971). It should also be noted that the corrected total recognition scores were unaffected by whether the judgment of number of words preceded or followed the recognition test. Neither the main effect of test order $[F(1.30)=0.68, p>.05]$ nor the interaction of Test Order by Groups $[F(1.30)=0.01 . p>.05]$ was significant.

\section{EXPERIMENT II}

Experiment II investigated the experience of duration in retrospect under conditions in which the number of events that occurred during the interval was constant. but the complexity of the sequence of events was varied. Two experiments reported by Ornstein (1969. Experiments III and IV) were also concerned with the effects of the complexity of a sequence of events. In these. 10 different events were repeated 20 times each. and the repetitions of the events were either massed ("easily codable") or distributed randomly ("random"). The experience of duration was lengthened in the latter 
condition relative to the former. Although no memory measures were taken, the literature on the effects of spacing of repetitions on memory (for a review, see Hintzman, 1974) strongly suggests that memory, as measured in a variety of ways, would have been greater in the "random" condition than in the "easily codable" condition. It would be desirable to investigate a situation in which memory decreases as the complexity of a sequence of events increases. For this purpose, Experiment II used a paradigm studied by Dallett (1964), Bahrick (1971), and many others. In this paradigm, different words that are instances of the same semantic category occur either in a block or randomly interspersed with instances of other categories. Typically, memory is greater in the blocked than in the random condition, and the effect is usually attributed to the greater degree of organization of memory storage and retrieval in the blocked condition. The main question of interest is: If duration judgments are affected by this manipulation, will they increase with the complexity (randomness) of the sequence or with an increase in memory for events occurring during the interval?

\section{Method}

\section{Materials and Design}

An audio tape consisting of three segments was recorded, with a 5 -sec blank interval between segments. The first segment. which was a $200-\mathrm{sec}$ excerpt of music from Aaron Copeland's Appalachain Spring. was recorded on one channel. The second segment was a 160 -sec blank interval, except for a series of 21 inaudible pulses that were recorded at 8 -sec intervals. The pulses were used to control the presentation of slides by a projector. Twenty slides were shown during the second segment, and four words were typed on each slide. The pool of words used in the experiment consisted of eight nouns in each of 20 categories from the Battig and Montague (1969) norms. In each category. the eight words selected had been given in response to the category label by at least $5 \%$ but not more than $25 \%$ of the Ss contributing to the norms. Categories were selected somewhat arbitrarily. so that eight words could be found that were not proper nouns. brand names. hyphenated words. etc. For example. four of the words from the category "a natural earth formation" were "ocean," "glacier." "cliff." and "rock." The 160 words were then divided into two sets of 80 . with each set containing four randomly selected words from each of the categories. For approximately half of the Ss. one set was used as experimental words. appearing on slides during the second segment, and the other set was used as distractor words. appearing only on the recognition test sheet: for the remaining Ss. the two sets were interchanged. The two main experimental groups differed only in the order of occurrence of instances of a given category. For Group B (blocked category instances), all four of the words appearing on a given slide were instances of the same category; but both the within-slide order of the words and the overall order of the slides was random. For Group R (random category instances). none of the four words appearing on a given slide were instances of the same category: otherwise. the particular words appearing on each slide. the within-slide order of the words, and the overall order of the slides was random. The third segment of the tape was a 140-sec excerpt of music from a different part of Appalachain Spring.

Duplicated test forms were again used for cach duration judgment. The order of the duration judgments was the same as in Experiment I. Instructions were also similar to those in Experiment I, except for the recognition test. On the yes-no recognition test sheet were typed all 160 words-the 80 that had been presented and the 80 that had not. Each block of 40 words contained 2 words from each category, 1 of which had been presented and 1 not. Otherwise, the order of the words was random.

\section{Subjects}

The Ss were 52 paid volunteers obtained in the same way as in Experiment I. None of them had participated in the previous experiment or any similar ones. They were tested in groups of three to six, and the order of the main experimental conditions was counterbalanced across testing sessions.

\section{Procedure}

Preliminary instructions were similar to those in Experiment I with the necessary modifications for visual presentation of the words. In addition. Ss were told that they would later be asked to write down as many of the words as they could remember. The Ss were not informed beforehand of any of the other tasks. including the duration judgments.

Test booklets were distributed immediately following the end of the tape. All Ss completed the test sheets in the same order. First. the three duration judgments were given, and 1.5 min was allotted for each. Instructions for the duration judgments were similar to those in Experiment I. Second, Ss were given 1 min to estimate the number of slides that had occurred. Third. they were given $5 \mathrm{~min}$ for free recall. Finally, on the yes-no recognition test, Ss were told to indicate whether or not each word on the test sheet had been presented; 4 min were allotted for this task.

\section{Results and Discussion}

In Table 2, the mean and standard deviation for each measure obtained in Experiment II are shown separately for Groups R and B. The tasks are listed and will be discussed in the order in which they were performed.

\section{Duration Judgments}

For the first duration judgment, the mean ratio of the judged length of the word interval to the standard length of the first music interval was significantly greater for Group B than for Group R [t(50) $=2.18, \mathrm{p}<.05]$. Thus, in comparison to the first music interval, retrospective duration judgments of the word interval were greater for the "less complex" sequence of words. For the second duration judgment, the mean ratio of the judged length of the word interval to the standard length of the second music interval did not differ significantly between the two groups $[\mathrm{t}(50)=1.14 . \mathrm{p}>.05]$. However, this nonsignificant difference was in the same direction as that of the first judgment. In addition, there was a significant correlation between individual S's first and second duration judgments $[r(50)=+.43, p<.01]$. revealing a consistency in the judgments. In other words, Ss who judged the word interval as long relative to the first music interval also judged it as long relative to the second music interval. For the third duration judgment. the mean ratio of the judged length of the first music 
Table 2

Mean and Standard Deviation (in Parentheses) fot Each Measure for Groups $R$ and B: Experiment II

\begin{tabular}{|c|c|c|c|c|c|c|c|c|c|c|}
\hline \multirow[b]{2}{*}{ Group } & \multicolumn{3}{|c|}{ Duration Judgments } & \multirow{2}{*}{$\begin{array}{l}\text { Judgment } \\
\text { of Number } \\
\text { Presented }\end{array}$} & \multicolumn{2}{|c|}{ Free Recall } & \multicolumn{4}{|c|}{ Recognition (Yes-No) } \\
\hline & $\begin{array}{c}\text { Segments } \\
2: 1 \\
\end{array}$ & $\begin{array}{c}\text { Segments } \\
2: 3 \\
\end{array}$ & $\begin{array}{c}\text { Segments } \\
1: 3 \\
\end{array}$ & & $\begin{array}{l}\text { Number } \\
\text { Correct }\end{array}$ & $\begin{array}{l}\text { Number } \\
\text { Produced }\end{array}$ & $\begin{array}{l}\text { Number } \\
\text { of Hits }\end{array}$ & $\begin{array}{l}\text { Number } \\
\text { of FAs }\end{array}$ & Corrected & $d^{\prime}$ \\
\hline $\mathbf{R}$ & $\begin{array}{c}0.76 \\
(0.24)\end{array}$ & $\begin{array}{c}1.14 \\
(0.35)\end{array}$ & $\begin{array}{c}1.51 \\
(0.39)\end{array}$ & $\begin{array}{l}54.2 \\
(18.6)\end{array}$ & $\begin{array}{l}9.1 \\
(4.5)\end{array}$ & $\begin{array}{c}11.2 \\
(4.9)\end{array}$ & $\begin{array}{c}39.4 \\
(12.5)\end{array}$ & $\begin{array}{c}11.0 \\
\left(\begin{array}{c}7.6)\end{array}\right)\end{array}$ & $\begin{array}{c}33.0 \\
(14.4)\end{array}$ & $\begin{array}{c}1.24 \\
(0.63)\end{array}$ \\
\hline B & $\begin{array}{c}0.89 \\
(0.21)\end{array}$ & $\begin{array}{l}1.25 \\
(0.29)\end{array}$ & $\begin{array}{c}1.46 \\
(0.37) \\
\end{array}$ & $\begin{array}{c}52.2 \\
(15.5)\end{array}$ & $\begin{array}{c}16.7 \\
(6.7)\end{array}$ & $\begin{array}{c}20.2 \\
(7.3)\end{array}$ & $\begin{array}{c}48.8 \\
(11.4)\end{array}$ & $\begin{array}{r}11.4 \\
(8.3)\end{array}$ & $\begin{array}{c}43.3 \\
(13.3)\end{array}$ & $\begin{array}{c}1.47 \\
(0.54)\end{array}$ \\
\hline
\end{tabular}

interval to the comparison length of the second music interval did not differ significantly between the two groups $[t(50)=0.44, p>05]$. For individual Ss, the third duration judgment was significantly correlated with both the first duration judgment $[\mathrm{r}(50)=-.43$, $p<.01]$ and the second duration judgment $[\mathrm{r}(50)=+.45 . \mathrm{p}<.001]$. revealing a further consistency in duration judgments that involve a common interval. (The negative correlation was expected because the first interval was the comparison interval for the first judgment and the judged interval for the third judgment.)

\section{Judgment of liumber of It'ords}

Each S's judgment of number of slides was multiplied by 4 , assuming that it was remembered that four words appeared on each slide. The resulting mean judgment of number of words presented did not differ significantly between Group B and Group R [t(50) =0.42. p > .05] . In this case, therefore. duration judgments apparently were not based on an aspect of memory similar to that which underlies judgment of number of events that occurred during the interval.

\section{Free Recall}

As expected, the mean number of words correctly recalled was significantly greater for Group B than for Group $\mathrm{R}[\mathrm{t}(50)=4.80 . \mathrm{p}<.001]$. In addition, the mean number of words produced in free recall, regardless of accuracy, was significantly greater for Group B than for Group R $[t(50)=5.20, p<.001]$. These results are a further replication of the finding that recall is superior for blocked as compared to random category instances (e.g.. Dallett, 1964). Presumably, blocking category instances enables Ss to store and retrieve the events in long-term memory in a more organized way.

\section{Recognition}

As in Experiment I. recognition performance was measured by both a standard correction for guessing and the d' statistic. In Experiment II. however, a yes-no recognition procedure was used. The mean number of words correctly recognized as having been presented (hits) was significantly greater for Group B than for Group $R[t(50)=2.82 . p<.01]$. In terms of the mean number of words incorrectly recognized as having been presented (false alarms). the two groups did not differ significantly $[t(50)=0.17, p>05]$. Using a standard correction for guessing. the resulting mean recognition score was significantly greater for Group $B$ than for Group R $[t(50)=2.72, p<.01]$. Lsing the d' statistic. the mean $d^{\prime}$ score did not differ significantly between the two groups $[t(50)=1.38 . p>.05]$. The difference between the two groups on the d' measure. however. was in the same direction as that on the correction for guessing measure. Blocking category instances apparently results in a superiority in recognition as well as in recall (e.g.. D'Agostino. 1969).

\section{GENERAL DISCUSSION}

The results of the two experiments reported here suggest that the experience of duration of an interval in retrospect is a cognitive construction based on the number of events stored and retained in long-term memory. Thus, these findings are consistent with Ornstein's (1969) storage size hypothesis. as well as with some other more vaguely worded ones. However. Ornstein proposed that two general factors determined the storage size of an interval, and the present results provide evidence for only one of the two. The results of both of the present experiments are consistent with the assumption that the storage size of an interval increases as the number of stored and retained events increases. The results of Experiment II. however. are not consistent with the assumption that storage size increases with an increase in the complexity (randomness) of a sequence of events-and. presumably, an increase in the complexity of the coding of the events. Although one might view the results of Experiment II as consistent with the complexity of coding assumption by stating that the blocked sequences were more complexly coded than the random sequences. this would clearly be an ad hoc interpretation of the results. Instead. it appears that the storage size of an interval at the time the duration judgment is made depends upon the degree of organization in memory of the events that occurred during the interval. When the sequence of events is more organized. more of the events are retained in memory. and the experience of duration is lengthened. This finding does not strictly disprove the assumption that the complexity of the coding of the events that occurred during an interval might be important under certain circumstances. However. it does indicate that Ornstein's interpretation of some of his 
experimental findings needs to be reexamined.

It is clear that an increase in the retained number of events occurring during an interval leads to a lengthening of the experience of duration in retrospect. One variable that can affect the retained number of events is the actual number of events (as in the present Experiment 1). but it is not the only important variable. As Ornstein (1969) acknowledged, some of his experiments (Experiments II, III, IV) on the effects of complexity of coding may be interpreted in terms of habituation to a repeated or persisting stimulus. Presumably, fewer external events enter into consciousness when habituation occurs, so fewer events would be retained in memory. A similar explanation is that when less attention is paid to external stimuli, duration experience shortens (cf. Fraisse, 1963).

Some other experimental findings that Ornstein interpreted as supporting a complexity of coding assumption can alternatively be seen to support the hypothesis that the experience of duration lengthens as the degree of organization of memory for the interval increases. For example (Ornstein, 1969, Experiment VI), Ss were trained to code or label segments of a film showing a dancer executing a sequence of modern dance movements. and then they viewed the entire film. The more categories (segments) into which Ss had learned to divide the film, the longer was the remembered duration of the film. In an analogous way, when Ss engaged in several different tasks during an interval, the experience of duration was lengthened relative to a condition in which they engaged in a single task (Harton. 1939). These findings have been interpreted as supporting the notion that, when the events that occurred during the interval were coded into fewer categories, the events were coded in a less complex or "better organized" way (Ornstein, 1969). However, Mandler and his colleagues have found that, at least within certain limits. there is a high positive correlation between the degree of organization of memory, defined as the number of categories used in a word-sorting task, and the number of words that is retained in memory, measured by either free recall or recognition (cf. Mandler, 1972). In other words, not only is memory presumably more organized when the availability of events occurring within a category is greater (as in the present Experiment II). but also when the number of categories into which the events have been coded is increased.

Similarly, when Ss were given a simple code for a complex experience, the experience of duration was shortened (Ornstein, 1969. Experiments VIII and IX), and it did not matter whether the code was supplied before or after the experience. According to the hypothesis outlined here, the effect may not be due to the complexity of the code of the experience in memory but rather to the nature of the organization of memory storage and retrieval for the interval. When a simple code was supplied before a complex figure was viewed. the experience may have been organized into a single category or interpretation of the figure. When the simple code was supplied after the figure had been viewed, the experience may have been originally organized into more than one category or interpretation, but the accessibility of the previously stored alternate interpretations of the figure may have been impaired.

In summary, the results of the present experiments, as well as some previous studies, suggest that the experience of duration is a cognitive construction based on the storage size of the interval. Storage size is assumed to increase as the number of stored and retained events increases, and this can be affected by several factors, including the degree of organization of long-term memory. One further question to which the present experiments are relevant concerns the process or mechanism by which $S$ assesses the storage size of the interval. In Experiment I, duration judgments were affected by a manipulation that did not affect free recall. Thus, storage size cannot be assessed solely in terms of the number of nominal stimulus events that could be free recalled from the interval, regardless of whether or not each recalled event actually occurred. In Experiment II, the experimental manipulation affected duration judgments but not judgments of number of events. Thus, storage size is apparently not assessed solely in terms of the number of nominal stimulus events that are construed to have occurred during the interval. Storage size might be assessed in terms of an aspect of long-term memory similar to that which underlies recognition performance, since Experiments I and II both showed a relationship between recognition memory and remembered duration. At present, however, there does not seem to be any simple explanation of why this should be the case. It seems more probable that some more complex retrieval process, which was not adequately measured in either of the present experiments, is involved in mediating the experience of duration. Future research in which both the experience of duration and memory processes are measured might reveal the nature of the constructive process that underlies the experience of duration in retrospect.

\section{REFERENCES}

Bahrick. H. P. Accessibility and availability of retrieval cues in the retention of a categorized list. Journal of Experimental Psychology. 1971, 89, 117.125

Battig. W. F., \& Montague, W. E. Category norms for verbal items in 56 categories: A replication and extension of the Connecticut category norms. Journal of Experimental Psychology. 1969. 80. Part 2. 1.46

Cooper. E. H.. \& Pantle. A. J. The total-time hy pothesis in verbal learning. Psychological Bulletin. 1967, 68, 221-234.

D'Agostino. P. R. The blocked-random effect in recall and recognition. Journal of Verbal Learning \& Verbal Behavior. 1969.8.815-820.

Dallett. K. II. Number of categories and category information in free secall. Journal of Liperimental Psychology. 1964. 68. $1-12$.

Darley. C. 1:. \& Murdock. B. B.. Ir. Lffects of prior free recall testing on final reciall and recoenition. Joumal of 
Experimental Psychology 1971.91.66-73.

Iraisse. P. The psichologi of time. ITranslated by J. Leitho New York: Harper \& Row. 1963

Frankenhaeuser. If Estimation of time. Stockholm: Amquist \& Wikiell. 1959.

Harton. I. J. The influence of the degree of unity of organization on the estimation of time. Journal of General Psychology. 1939. $21.25-49$.

Hintzman. D. L. Theoretical implications of the spacing effect. In R. L. Solso (Ed.). Theories of cognitive psicholog.: The Lorola simpositm. Washington. D.C: Winston. 1974.

Kintsch. W. Learning. memory and conceptual processes. New York: Wiley, 1970.

Mandler. G. Organization and recognition. In E. Tulving and W. Donaldson iEds.l. Organization and memory. New York: Academic Press. 1972.
Mckeon. R. P. (Ed.). The basic works of Aristotle. New York: Randon House. 1941.

Michon. J. A. Processing of temporal information and the cognitive theory of time experience. Studium Generale. 1970. 23. 249-265.

Neisser. L'. Cognitive psychologr. New York Appleton-Century-Crofts. 1967.

Ornstein. R. E. On the experience of time. Harmondsworth. Middlesex. England: Penguin. 1969.

(Received for publication May 25, 1973; revision received July 12,1973 .) 